UDK: 005:368

DOI: $\underline{\text { https://doi.org/10.24867/12GI27Macasev }}$

\title{
UNAPREĐENJE PROCESA REALIZACIJE SISTEMA PENZIJSKOG I INVALIDSKOG OSIGURANJA
}

\section{PROCESS IMPROVEMENT OF PENSION AND DISABILITY INSURANCE SYSTEM}

\author{
Aleksandra Maćašev, Fakultet tehničkih nauka, Novi Sad
}

\section{Oblast - INDUSTRIJSKO INŽENJERSTVO I MENADŽMENT}

Kratak sadržaj - U radu su predstavljene teorijske osnove sistema menadžmenta kvaliteta i primena u oblasti penzionog sistema. Cilj rada je da se prikažu procesi, analiziraju najznačajniji problemi $i$ predlože zaštitne mere za unapređenje procesa realizacije sistema penzijskog i invalidskog osiguranja.

Ključne reči: penzija, penzijsko i invalidsko osiguranje

\begin{abstract}
This paper presents the theoretical foundations of quality management systems and it's realization in the pension system area. The aim of this paper is to present the processes, analyze the most significant problems and propose protective measures to improve implementation of the pension and disability insurance system
\end{abstract}

Keywords: pension, pension and disability insurance,

\section{UVOD}

Penzijsko i invalidsko osiguranje predstavlja najznačajniji deo socijalnog osiguranja. Sadašnje generacije zaposlenih lica uplaćuju doprinose iz kojih se isplaćuju penzije i na taj način stiču pravo da budu finansirane od strane budućih generacija. Penzija je mesečna novčana naknada i druge benficije na koje pojedinac stiče pravo po osnovu osiguranja za slučaj starosti, invalidnosti i smrti, a pod uslovima utvrđenim zakonom [2]. U Republici Srbiji pružanje usluga obaveznog socijalnog, penzijskog i invalidskog osiguranja obavlja Republički fond za PIO.

Proces realizacije sistema penzijskog i invalidskog osiguranja Republički fond za PIO sprovodi na osnovu definisanih i dokumentovanih procedura rada. Uspostavljen je integrisani sistem upravljanja kvalitetom (standard ISO 9001:2015) i sistem upravljanja bezbednošću informacija (standard ISO 27001:2013).

Teorijska osnova master rada je sistem menadžmenta kvalitetom. Predmet istraživanja rada je proces realizacije sistema penzijskog i invalidskog osiguranja i za analizu su izdvojena dva procesa: proces ostvarivanja prava iz PIO po međunarodnim sporazumima i proces medicinskog veštačenja. Analizirani su uzroci koji mogu da utiču na povećanje ažurnosti i efikasnosti poslovanja: analiza potencijalnih uticaja na vremenski period obrade zahteva i analiza potencijalnih uticaja na ostvarivanje penzije bez zakonskog osnova (lažirane penzije). Analize potencijalnih uzroka uticaja prikazane su Ishikawa dijagramom. $\mathrm{Za}$ identifikovane potencijalne uzroke uticaja urađena je ocena rizika primenom FMEA metode i predložene su mere za rešavanje potencijalnih problema.

Cilj rada jeste da se definišu zaštitne mere i sprovede poboljšanje procesa realizacije sistema penzijskog i invalidskog osiguranja, kako bi se kvalitet usluga podigao na viši nivo.

\section{SISTEM MENADŽMENTA KVALITETOM}

Razvijanje sistema menadžmenta kvalitetom podrazumeva potpuno upravljanje u organizaciji: utvrđivanje politike, ocenu stanja, projektovanje, izgradnju, sertifikaciju, održavanje i unapređenje sistema menadžmenta kvalitetom.

Upravljanje procesima i unapređenje kvaliteta postiže se donošenjem odluka na osnovu činjenica uz pomoć korišćenja metoda i tehnika kvaliteta.

Metode i tehnike unapređenja procesa rada našle su veliku primenu $\mathrm{u}$ industriji, a naročito $\mathrm{u}$ kontroli kvaliteta. Koriste se statističke, inženjerske i menadžerske metode. Inženjerske metode razvili su inženjeri u cilju rešavanja identifikovanih problema pri kontroli i upravljanju kvalitetom. Tu spadaju: dijagram toka, Ishikawa dijagram, matrični dijagram, FTA, FMEA I FMECA (metode analize neispravnosti i otkaza), QFDA metoda. $\mathrm{Za}$ analize potencijalnih uzroka problema $\mathrm{u}$ procesu realizacije sistema penzijskog $\mathrm{i}$ invalidkog osiguranja korišćene su: dijagram toka, Ishikawa dijagram i FMEA metoda.

Dijagram toka predstavlja grafički prikaz opisa nekog procesa redoslednim povezivanjem odvijanja aktivnosti $\mathrm{u}$ samom procesu. Koristi se za prikazivanje snimka postojećeg procesa i procesa koji se projektuju.

Ishikawa dijagram predstavlja metodu za detaljnu analizu odnosa između određenog stanja sistema (posledice) i uticajnih veličina (uzroka) koje uslovljavaju pojavu datog stanja [1].

FMEA metoda predstavlja sistematičan proces za identifikaciju potencijalnih otkaza u nekom sistemu i preventivne akcije kako bi se smanjio rizk nastajanja otkaza. Benefiti od prevencije su brojni i utiču na performanse proizvoda/usluga.

\section{NAPOMENA:}

Ovaj rad proistekao je iz master rada čiji mentor je bio dr Dragoljub Šević, vanr. prof. 


\section{SNIMAK STANJA I ANALIZA MOGUĆIH PROBLEMA U PROCESU REALIZACIJE SISTEMA PENZIJSKOG I INVALIDSKOG OSIGURANJA}

U ovom poglavlju urađen je snimak stana, opisan i analiziran proces ostvarivanja prava iz PIO po međunarodnim sporazumima. $\mathrm{Na}$ osnovu dobijenih podataka prikazan je dijagram toka i urađena je analiza potencijalnih uticaja na ostvarivanje penzije bez zakonskog osnova (lažirane penzije). Analiza je prikazana Ishikawa dijagramom, a potencijalni rizici su ocenjeni FMEA metodom.

\subsection{Snimak stanja}

U Republičkom fondu za PIO se obavlja: utvrđivanje svojstva osiguranika, utvrđivanje svojstva korisnika prava $\mathrm{i}$ isplata penzija $\mathrm{i}$ drugih naknada.

Dnevno poslovanje se obavlja veoma složeno, sa više odeljenja i osoba koje su uključene u proces. Proces otpočinje predajom zahteva i prateće dokumentacije za ostvarivanje prava iz PIO od strane osiguranika, koji predstavljaju ulazne podatke. Oni su u pisanoj formi (zahtev, dokumenti) i kao i većina poslovnih procesa baziraju se na ručnom unosu i ručnoj kontroli unetih podataka u poslovne aplikacije. Unos istih podataka može da bude na različitim mestima (mnogo korisničkih interfejsa), što rezultira mogućnošću nastajanja grešaka. Često podaci iz zahteva i prateće dokumentacije, i podaci u Matičnoj evidenciji nisu isti, stoga se u proces uključuju filijale, ostale državne institucije, države, pa i sami korisnici, što dodatno komplikuje naredne procese. Značajno je izdvojiti i problem zloupotrebe penzija koji uzrokuje velike materijalne štete, jer se sve češće javljaju razne vrste odstupanja i manipulacije sa podacima, što rezultira nastajanju lažiranih penzija.

\subsection{Analiza procesa ostvarivanja prava iz PIO po međunarodnim sporazumima}

Republika Srbija ima potpisane sporazume sa 29 zemalja (Bilateralni međunarodni sporazumi). U bilateralnim međunarodnim sporazumima su uređena pitanja radnog staža, zdravstvenog osiguranja, isplate penzija i dr.

U procesu ostvarivanja prava iz PIO po međunarodnim sporazumam učestvuju: stručni saradnik za ostvarivanje prava iz PIO po međunarodnim sporazumima, stručni saradnik za ostvarivanje prava iz PIO - kontrolor, stručni saradnici matične evidencije, referenti za administrativne poslove pisarnice, referenti za administrativne poslove arhive, refrenti za administrativne poslove ekspedicije, načelnik i pomoćnik načelnika odeljenja. Proces započinje podnošenjem zahteva i podnesaka od strane osiguranika na šalteru pisarnice. U pisarnici referent za administrativne poslove pisarnice vrši prijem i zavođenje zahteva. Formirani spis predmeta prosleđuje Sektoru za ostvarivanje prava iz PIO po međunarodnim sporazumima ukoliko se odnosi na starosnu i porodičnu penziju, a ukoliko se zahtev odnosi na invalidsku penziju Sektoru za medicinska veštačenja, na dalji postupak. U Sektoru za ostvarivanje prava iz PIO po međunarodnim sporazumima, stručni saradnik za ostvarivanje prava iz
PIO vrši obradu zahteva. Ukoliko podaci nisu kompletni spisom predmeta se zadužuje stručni saradnik matične evidencije koji vrši kompletiranje podataka. Nakon kompletiranja podataka, spis predmeta se vraća stručnom saradniku za ostvarivanje prava iz PIO po međunarodnim sporazumima koji pristupa izradi nacrta rešenja. Nacrt rešenja i spis predmeta dostavljaju se stručnom saradniku za ostvarivanje prava iz PIO po međunarodnim sporazumima - kontroloru na kontrolu. Ukoliko je data saglasnost, nacrt rešenje se dostavlja načelniku odeljenja na verifikaciju. Ukoliko nije data saglasnost, rešenje se neposredno vraća na ponovni postupak. Potpisano rešenje dostavlja se ekspediciji radi otpremanja podnosiocu zahteva i arhivi radi čuvanja (zajedno sa spisom predmeta).

U procesu ostvarivanja prava iz PIO po međunarodnim sporazumima identifikovane su sledeće aktivnosti: prijem i zavođenje zahteva, obrada zahteva za ostvarivanje prava iz PIO, kompletiranje podataka u matičnoj evidenciji, donošenje rešenja o pravu iz PIO, kontrola rešenja o pravu iz PIO, verifikacija rešenja o pravu iz PIO, ekspedicija rešenja o pravu iz PIO i arhiviranje spisa predmeta.

Narednom slikom predstavljen je dijagram toka procesa ostvarivanja prava iz PIO po međunarodnim sporazumima izrađen na osnovu analize procesa, opisa procesa, definisanja aktivnosti i opisa aktivnosti u samom procesu (Slika 1).

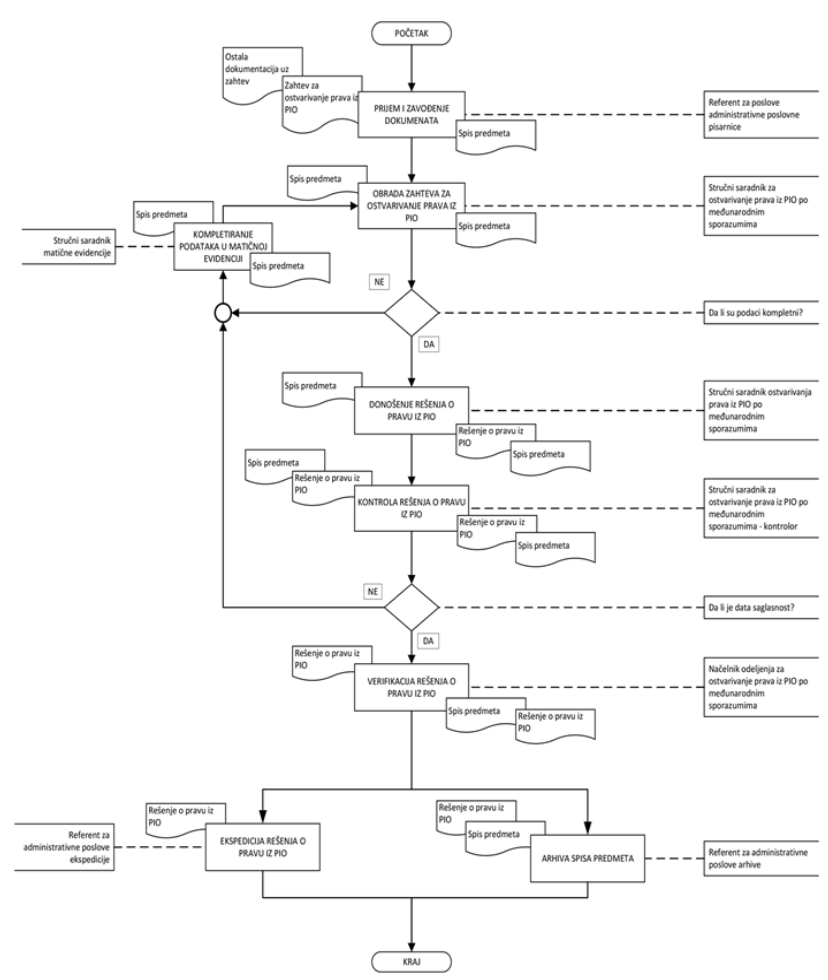

Slika 1. Dijagram toka procesa ostvarivanja prava iz PIO po međunarodnim sporazumima

Slika je rezultat istraživačkog rada autora

\subsection{Analiza mogućih uzroka lažiranja penzija}

Postizanje kvalitetnijih usluga korisnicima/osiguranicima ostvaruje se povećanjem ažurnosti u rešavanju o PIO i zbog toga su analizirani uticaji na vremenski period 
obrade zahteva i uticaji na ostvarivanje penzije bez zakonskog osnova (lažirane penzije). Ovom prilikom predstaviće se analiza lažiranja penzija Ishikava dijagramom, primeni će se FMEA metoda i predložiti zaštitne mere za rešavanje potencijalnih problema.

Republički fond za PIO ima za cilj da omogući osiguranicima da ostvare prava iz PIO u skladu sa Zakonom o PIO, odnosno da se procesi i postupci odvijaju na potpuno pravilan i zakonit način. Međutim, ponekad mogu da se dese odstupanja i manipulacije $u$ procesima i postupcima koji dovode do lažiranja penzija. Svi identifkovani potencijalni uzroci (efekti) razvrstani su u 4 grupe, kombinacijom kategorizacije 4M i 4P. Grupa potencijalnih uzroka vezana za UČESNIKE, grupa potencijalnih uzroka vezana za DOKUMENTACIJU, grupa potencijalnih uzroka vezana za PROCEDURE i grupa potencijalnih uzroka vezana za PRAVILA.

Prva grana Ishikawa dijagrama su grupa potencijalnih uzroka UČESNICI. U datoj grani horizontalne linije čine prestupi grupisani prema vrsti učesnika u procesu: prestupi podnosioca zahteva, prestupi zaposlenih i prestupi ostalih učesnika drugih institucija. Druga grana Ishikawa dijagrama je grupa potencijalnih uzroka DOKUMENTACIJA. Na horizotalnim linijama dijagrama uzroci su podeljeni u odnosu na sadržinu podataka: dokumentacija sa neistinitom sadržinom podnosioca zahteva, neispravno izdata dokumentacija sa namerom i neispravna dokumentacija omaškom. Treću granu Ishikawa dijagrama čini grupa potencijalnih uzroka PROCEDURE. U ovoj grupi potencijalni uzroci su razvrstani na: pogrešna primena i nepoštovanje procedura rada. Oni su predstavljeni horizontalnim linijama na dijagramu. Poslednju granu Ishikawa dijagrama čini grupa osnovnih potencijalnih uzroka PRAVILA. Na horizontalnim linijama pravila su podeljena u odnosu na primenu: pogrešno tumačenje i nepoštovanje Zakona i Statuta fonda za PIO. Razvrstavanje je urađeno do elementarnih potencijalnih uzroka koji se mogu meriti i na koje se može uticati. Konačan izgled Ishikawa dijagrama prikazan je sledećom slikom (Slika 2).

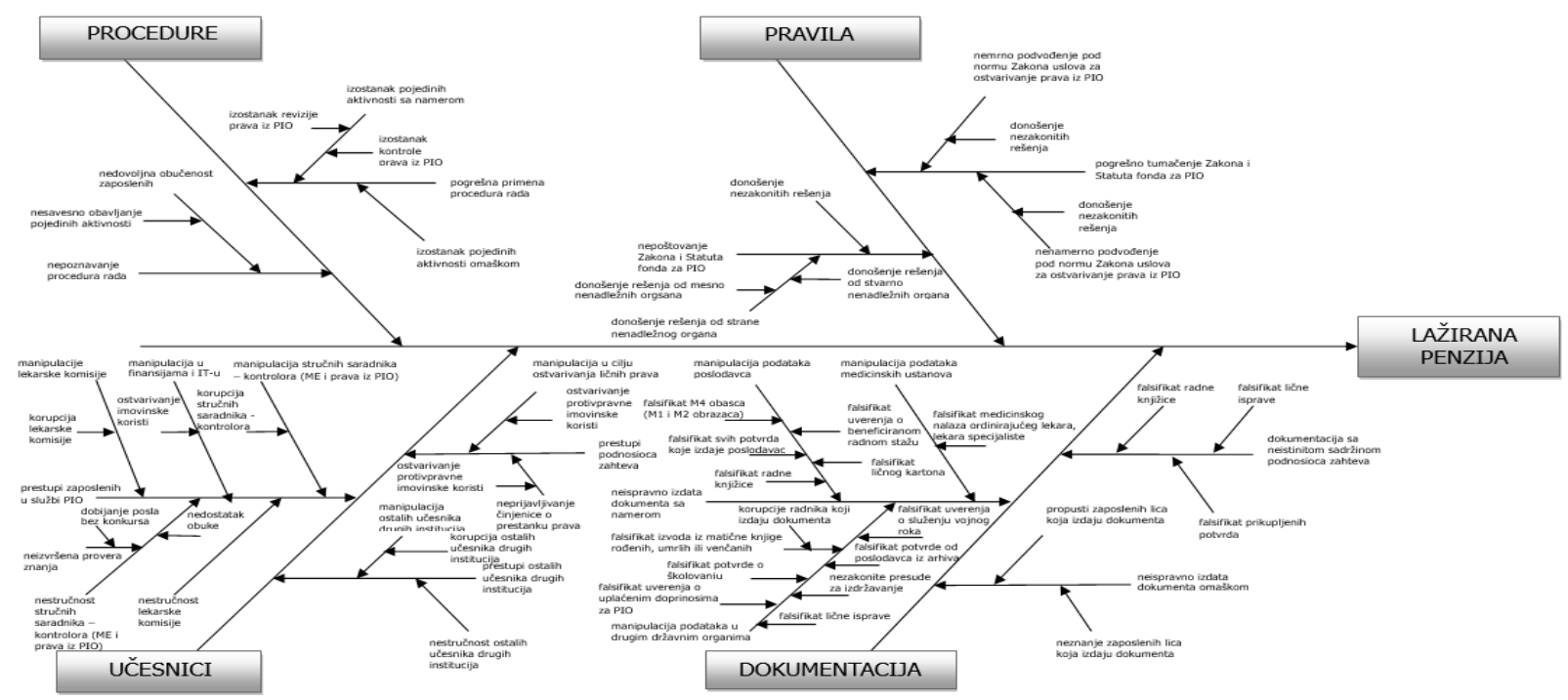

Slika 2. Konačan izgled Ishikawa dijagrama za potencijalne uzroke lažiranja penzija Slika je rezultat istraživačkog rada autora

\section{4 FMEA analiza}

Nakon identifikovih potencijalnih uzroka primenjena je FMEA metoda i predložene su zaštitne mere.

Najčešće verovatnoću rizičnog događaja nije moguće precizno odrediti, zbog čega se primenom odgovarajućih tabela verovatnoća prevodi u numeričke vrednosti. Prevođenje potencijalnih uzroka lažiranja penzija predstavljeno je narednom tabelom (Tabela 1).

Tabela 1. Prevođene verovatnoće potencijalnih uzroka lažiranja penzija u numeričke vrednosti

\begin{tabular}{|c|c|c|c|c|c|c|}
\hline \multicolumn{2}{|c|}{ 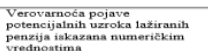 } & \multicolumn{2}{|c|}{ 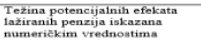 } & \multicolumn{3}{|c|}{\begin{tabular}{|l} 
Moguchoost otkrivanja potencijalnih uzroka \\
iażiranih penzzija
\end{tabular}} \\
\hline VEROVATNOĆA & OCENA & TEZ̈INA & OCENA & opIs & $\begin{array}{l}\text { VERORATNOCA } \\
\text { OTKRIVNASA }\end{array}$ & OCENA \\
\hline $\begin{array}{c}\text { Jednom un pet } \\
\text { goding }\end{array}$ & 1 & $\begin{array}{l}\text { Materijalina steta } \\
\text { ispod } 5000.000,00 \\
\text { dinara }\end{array}$ & 1 & 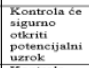 & Veoma visoka & 1 \\
\hline $\begin{array}{l}\text { Jednom u Eetiri } \\
\text { godine }\end{array}$ & 2 & 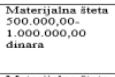 & 2 & 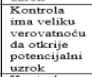 & Visoka & 2 \\
\hline $\begin{array}{l}\text { Jednom u tri } \\
\text { godine }\end{array}$ & 3 & 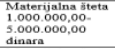 & 3 & 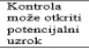 & Srednja & 3 \\
\hline $\begin{array}{l}\text { Jednom u dve } \\
\text { godine }\end{array}$ & 4 & 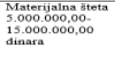 & 4 & 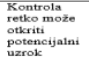 & Niska & 4 \\
\hline Jednom u godini & 5 & $\begin{array}{l}\text { Materijalna Siteta } \\
\text { proveo } \\
\text { 15.000.000,00 } \\
\text { dinara }\end{array}$ & 5 & 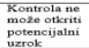 & Veoma niaka & $s$ \\
\hline
\end{tabular}

Za rangiranje rizika koristi se RPN metoda kojom se dobija ocena rizika kao proizvod numeričke vrednosti učestalosti, težine i detekcije. Kada se izračuna vrednost RPN za sve kvantifikovane opasnosti i uticaje, definišu se granice prihvatljivosti rizika kao u narednoj tabeli (Tabela 2).

Tabela 2. Definisanje granice rizika lažiranih penzija

\begin{tabular}{|c|c|}
\hline $\begin{array}{c}\text { Ocena rizika } \\
(\text { RPN })\end{array}$ & Rizik \\
\hline do 40 & mali \\
\hline $40-80$ & umeren \\
\hline preko 80 & neprihvatljiv \\
\hline
\end{tabular}

Nakon utvrđivanja numeričkih vrednosti verovatnoće, narednom tabelom (Tabela 3) predstavljen je FMEA obrazac sa utvrđenim, definisanim i rangiranim potencijalnim uzrocima lažiranja penzija. 
Tabela 3. FMEA obrazac lažiranja penzija

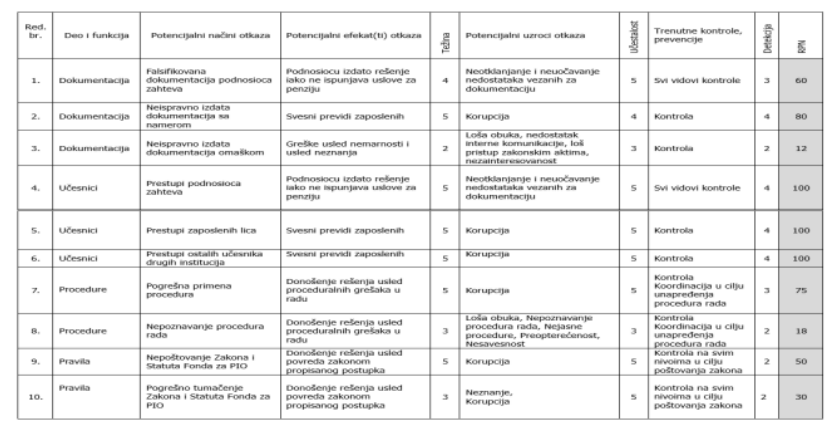

\section{PREDLOG ZAŠTITNIH MERA ZA} POTENCIJALNE UZROKE LAŽIRANJA PENZIJA

$\mathrm{Na}$ osnovu rezultata dobijenih iz FMEA obrazaca izdvojena su tri najznačajnija potencijalna uzroka problema (najveće vrednosti RPN): prestupi podnosioca zahteva, prestupi zaposlenih i prestupi ostalih učesnika drugih institucija. Za pomenute potencijalne uzroke izrađen je predlog zaštitnih mera i definisani su postupci koji će ublažiti/eliminisati posledice analiziranih potencijalnih problema.

Prva zaštitna mera za liniju kritičnog uzroka - prestupi podnosioca zahteva je povećanje kontrole prilikom preuzimanja zahteva, povećanje broja referenata $\mathrm{i}$ kontrolora i uvođenje vođenja kontrolnika. Druga zaštitna mera je unapređenje kompetencija zaposlenih koji primaju zahteve i unose podatke, kroz obuke i stručno usavršavanje. Treća zaštitna mera je pooštravanje kaznenih odredbi i preciziranje postojanja krivičnih dela u ovoj oblasti, jer se prema odredbama Zakona o PIO trenutno tretiraju kao prekršaji.

Prva zaštitna mera za liniju kritičnog uzroka - prestupi zaposlenih je ugradnja kontrolnih mehanizama u aplikacije za pristupe i izmene podataka (ko je uradio izmenu, kada, sa kog mesta i dr.), čime bi se minimizirale moguće manipulacije u procesima podrške (finansijski sektor, sektor IT).

Druga preporučena zaštitna mera jeste analiza kadrovske strukture i reorganizacija, pri čemu bi osnov za sistematizaciju radnih mesta bila usluga. To znači povećanje broja kontrolora u odnosu na izvršioce usluga (povećanje broja kontrolora u ME, kontrolora u ostvarivanju prava iz PIO, lekara veštaka). Treća preporučena zaštitna mera je uvođenje kaznenih mera za zaposlene, po mogućnosti i sistema nagrađivanja, kao vid stimulacije.

Predlog zaštitnih mera za liniju kritičnog uzroka prestupi ostalih učesnika drugih institucija je unapređenje tehničke opremljenosti, odnosno unapređenje e - Uprave (elektronska razmena podataka sa državnim i drugim institucijama).

Do potpune integracije sa e - Upravom predloženo je obezbeđivanje potrebne dokumentacije po službenoj dužnosti od državnih i ostalih institucija.

\section{FMEA NAKON SPOVEDENIH ZAŠTITNIH MERA}

Nakon definisanja zaštitnih mera ponovo je urađena FMEA analiza, prikazana u narednoj tabeli (Tabela 4).
Tabela 4. FMEA analiza nakon sprovedeih zaštitnih mera

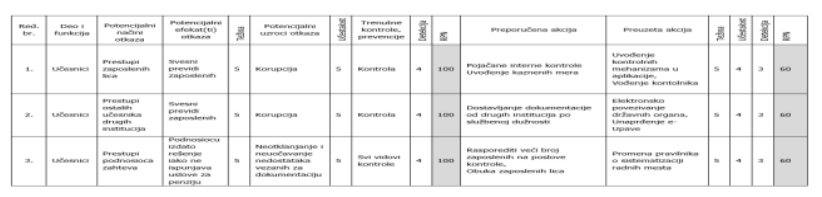

Iz FMEA tabele nakon sprovedenih zaštitnih mera vidi se da su potencijalni rizici $(\mathrm{RPN}=100)$ svedeni na prihvatljivu meru (RPN=60).

\section{ZAKLJUČAK}

Glavni cilj u Republičkom fondu za PIO jeste unapređenje usluga osiguranicima/korisnicima. To podrazumeva povećanje produktivnosti rada, adekvatne procedure rada, stručne i kompetentne kadrove, bolju komunikaciju interno i eksterno, kao i podršku moderne tehnologije.

Analiza lažiranja penzija pokazuje da se dešavaju razni prestupi i da se falsifikuju razna dokumenta, sa ciljem sticanja uslova za ostvarivanje prava iz PIO. Dokumenta može da falsifikuje podnosilac zahteva, zaposleni ili zaposleni u ustanovama koje izdaju dokumenta.

Prestupi podnosioca zahteva se trenutno, prema odredbama Zakona tretiraju kao prekršaji za koje su predviđene novčane kazne. Potrebno je neposrednom primenom zakonskih odredbi pooštriti i povećati kaznene odredbe za prekršaje podnosioca zahteva i precizirati postojanje krivičnih dela $\mathrm{u}$ ovoj oblasti. Isto tako, potrebno je i uvođenje novčanih kazni za zaposlena lica. Elektronsko povezivanje svih državnih institucija i pribavljanje dokumentacije po službenoj dužnosti sprečilo bi izdavanje falsifikovane i neispravne dokumentacije. Osnivanje Centralnog registra (povezivanje sa Poreskom Upravom) i e - Uprave možemo posmatrati kao jednu od mera u sprečavanju manipulacije kod određivanja pripadanja $\mathrm{i}$ visine penzije. U budućnosti, potpunom integracijom Republičkog fonda za PIO sa e - Upravom omogući će se brži i efikasniji servis, skraćenje upravnog postupka, povećanje transparetnosti i dostupnosti, smanjenje papirologije, lakšu komunikaciju, sprečavanje koruptivnih radnji i drugih vidova kriminala.

Na kraju se može zaključiti, da svaka organizacija mora da radi na unapređenju poslovanja, jer samo na taj način može da ostvari dugoročan opstanak, što, kada je reč o organizaciji obaveznog socijalnog osiguranja ima širi društveni značaj.

\section{LITERATURA}

[1] Dr V. Vulanović, et al., "Metode i tehnike unapređenja procesa rada", Univerzitet u Novom Sadu, Fakultet tehničkih nauka, Departman za industrijsko inženjerstvo, IIS Istraživački i tehnološki centar, Novi Sad, 2012

[2] https://sh.wikipedia.org/wiki/penzija (datum pristupa: 2016-09-20)

\section{Kratka biografija:}

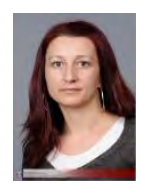

Maćašev Aleksandra rođena je u Novom Sadu 1976. godine. Master rad na Fakultetu tehničkih nauka iz oblasti Industrijsko inženjerstvo i menadžment odbranila je 2020. godine. kontakt: sandra.macasev@gmail.com 